\title{
Young children capitalising on their entire language repertoire for language learning at school
}

\section{Claudine Kirsch}

To cite this article: Claudine Kirsch (2017): Young children capitalising on their entire language repertoire for language learning at school, Language, Culture and Curriculum, DOI: 10.1080/07908318.2017.1304954

To link to this article: http://dx.doi.org/10.1080/07908318.2017.1304954

\section{+ View supplementary material}

\section{曲 Published online: 24 Mar 2017.}

Submit your article to this journal

Q View related articles $\sqsubset$

View Crossmark data $\nearrow$ 


\section{Young children capitalising on their entire language repertoire for language learning at school}

\section{Claudine Kirsch}

Faculty of Language and Literature, Humanities, Arts and Education, University of Luxembourg, Esch-surAlzette, Luxembourg

\begin{abstract}
While translanguaging has been well researched in bilingual settings with older pupils and has been found to contribute to cognitive and personal development, there is little research on translanguaging of young multilinguals. In trilingual Luxembourg, at school, children learn Luxembourgish aged 4, German aged 6 and French aged 7 , with the majority not speaking Luxembourgish on school entry. The number of languages to be learned may leave teachers little space to capitalise on home languages and encourage translanguaging. Drawing on qualitative methods, this paper contextualises and examines the practice and purposes of translanguaging of nursery and primary school children who speak a language other than Luxembourgish at home, while they collaboratively produce oral texts on the iPad app iTEO. The data stem from a longitudinal study using a multi-method approach. The findings indicate that the children made use of their multilingual repertoire in order to communicate, construct knowledge and mark their multilingual identity. Translanguaging was a frequent and legitimate practice in both classes although the older children drew less on home languages other than Luxembourgish. The children's ability to translanguage and their opportunities for doing so were influenced by the multilingual learning environment, the curriculum and the language learning tasks.
\end{abstract}

\section{ARTICLE HISTORY}

Received 30 August 2016

Accepted 5 March 2017

\section{KEYWORDS}

Multilingualism;

translanguaging;

Luxembourg; nursery; primary school; ipad app iTEO

\section{Introduction}

School intakes are increasingly heterogeneous in most countries and children of immigrant origin are at risk of underperforming. They are under pressure to quickly learn a country's language(s) in order to access the curriculum. In trilingual Luxembourg, a small country bordering France, Belgium and Germany, the pressure on young children is particularly strong because they must learn the country's three official languages from primary school - Luxembourgish, German and French. Most residents make daily use of several languages and switch languages often. As Fehlen and Heinz (2016) reported, the most common oral languages used at work are French (68\%) and Luxembourgish (60\%), followed by German (34\%), English (28\%) and Portuguese (14\%). Luxembourgers use Luxembourgish among themselves and mainly French to communicate with non- 
Luxembourgish-speaking residents. On 1 January 2016, 47\% of the residents did not have Luxembourgish citizenship, the majority being Portuguese, French and Italian (MENJE, 2016). Of particular interest to this study is the language use of 4-year-olds who enter nursery school. Of these, 35\% speak Luxembourgish at home, 29\% Portuguese and 36\% 'other' languages such as French, Serbo-Croat or Albanian. Faced with such a high and steadily increasing number of children who do not speak the national language, the Ministry of National Education, Childhood and Youth (MENJE) asked educators to focus on Luxembourgish in the précoce, a non-compulsory nursery school year, and in the twoyear-long compulsory nursery school.

The present paper investigates the influence of classroom language practices on nursery and primary school children's translanguaging and examines the practices and purposes of their translanguaging in situations where they collaboratively produce oral texts on the app iTEO. The selected children did not acquire Luxembourgish at home. Researchers have shown that translanguaging can contribute to the development of language skills and raise attainment (García \& Sylvan, 2011; Williams, 2002). As the majority of studies in this field were carried out with secondary school and university students in bilingual settings, Lewis, Jones, and Baker (2012) called for research projects with both younger children and those in multilingual settings. Drawing on qualitative research methods, this paper will show that the emergent multilinguals, aged between 4 and 8 , draw on their multilingual repertoire most of the time and that translanguaging enables them to communicate, construct knowledge, develop their multilingual competence and mark their multilingual identity. The findings have to be seen in relation to the learning environment and the digital language learning activities and are of particular relevance to teachers interested in implementing multilingual pedagogies.

\section{Schooling in Luxembourg and the app iTEO}

The education system in Luxembourg is trilingual; however, it is underpinned by a monoglossic view and language skills are developed in an isolated and compartmentalised manner (De Korne, 2012). One of the aims of the curriculum of the nursery school is for children to express themselves in Luxembourgish using simple language when speaking about familiar topics by the time they enrol in primary school (MENFP, 2011). This is a challenging task given that $65 \%$ of the 4 -year-olds do not speak Luxembourgish. Understandingly, teachers focus on this language. The primary school curriculum prescribes that pupils become literate in German in Year 1, learn oral French from Year 2 and written French from Year 3. Language instruction, which accounts for $40.5 \%$ of all curricular time, is separated into predefined time slots for each language and largely based on individualised and formalised pencil and paper work. As in many other countries, the system privileges written and decontextualised language and literacy practices (Hornberger \& Link, 2012). The curriculum additionally states that the languages of instruction are Luxembourgish and German, the former in non-academic subjects and the latter in academic ones. Teachers may reprimand children if they use Luxembourgish or home languages in maths or science lessons, as these are the 'wrong' languages. Language education has always to be seen within its social and political context, in which it is situated. It advantages some actors while disadvantaging others. In Luxembourg, children of language minority groups frequently have difficulties accessing the curriculum and underachieve. 
Large-scale assessment studies have consistently highlighted a strong correlation between social-economic status, ethnic minority background and poor achievement (Martin, Ugen, \& Fischbach, 2015).

In order to promote inclusive and innovative methods of language teaching, the Ministry of Education encouraged Gretsch and Kirsch, researchers at the University of Luxembourg, to further develop the app iTEO, which draws on Bakhthin's theory of dialogism and on social-constructivist language learning theories. The iPad app allows users to record and edit oral text of any length. The recording appears as a numbered icon on the interface. Users can edit their oral text by rearranging and deleting these icons. They may also add written text and insert pictures with the iPad camera. They can listen to selected items or the entire oral production at will. (In what follows, the word 'text' will refer to 'oral text'.) One of the most important features is the automatic replay. It materialises the language used, thereby providing opportunities for revision, analysis, negotiation of meanings, and interpretations of discourse. The opportunity to endlessly transform language pays tribute to the unpredictability and negotiability of authentic language use.

\section{Translanguaging within multilingual contexts}

Many theories of second-language learning are indebted to conservative views of bilingualism that suggest that languages are learned in a linear way and are best taught separately. It was assumed that a strict separation of languages was the only way to avoid 'cross-contamination' (Jacobson \& Faltis, 1990). By contrast, an analysis of the language practices of bilinguals indicates that they use their entire language repertoire in a dynamic and flexible way (García \& Li Wei, 2014).

Multilingual pedagogies are based on a dynamic view of bilingualism and are, according to Haukas (2016, p. 2), a 'set of principles' used 'to varying degrees in different approaches depending on the teaching context, curriculum and learners'. Among these are language awareness approaches and tertiary language didactics that encourage the analysis of similarities and differences between languages. In the context of this paper, I build particularly on the work of, for instance, educators and researchers around García in the U.S.A. as well as Creese and Blackledge in the U.K. who worked with bilinguals mainly in mainstream and complementary schools and developed ways of teaching languages in an inclusive and meaningful way. These pedagogies require practitioners, first, to provide all learners with equal opportunities to participate and develop multilingualism, and, second, build on social-constructivist theories, which call for quality interactions, dialogue and collaboration (García \& Flores, 2011). This approach has been shown to raise student achievement (García \& Sylvan, 2011). Translanguaging is a pillar of this pedagogy as it allows teachers and learners to make meaning 'across' languages.

The term translanguaging was coined by Williams (2002) to denote a pedagogy in Wales that calls for the systematic switching of languages for reception and production. García and Li Wei (2014) expanded this definition to combine linguistic, sociolinguistic and psycholinguistic perspectives. Otheguy, García, and Reid (2015, p. 281) define translanguaging as 'the deployment of a speaker's full linguistic repertoire without regard for watchful adherence to the socially and politically defined boundaries of named (and usually national and state) languages'. The authors maintain that translanguaging offers an insider's perspective on the deployment of a speaker's idiolect, which contrasts with 
an outsider's perspective that focuses on the named languages used. Li Wei's (2011) definition of translanguaging draws on the notion of 'languaging' (Pennycook, 2010). The latter emphasises that people do not have 'one' or 'two' languages. Rather, they use 'language', that is, mobile linguistic resources, to communicate. Li Wei holds that translanguaging is a situated holistic performance where individuals draw on and weave together a range of abilities, experiences, attitudes and ideologies (2011, p. 1222). In socalled translanguaging spaces, individuals critically and creatively engage with their own experiences and those of others, which, in turn, can transform individuals, practices and society (García \& Li Wei, 2014). Thus, according to García and Li Wei, language and translanguaging are social phenomena embedded in particular social, economic and political contexts.

Translanguaging as a pedagogy can be transformative because it gives all students access to the curriculum, promotes dialogic teaching and can raise achievement. Several scholars have researched the potential of translanguaging for learning. García (2011) and Esquinca, Araujo, and de la Piedra (2014), who have researched translanguaging of emergent bilingual nursery and primary school children in New York and at the U.S-Mexican border, respectively, reported that children used translanguaging to construct meaning and mediate understanding. Lewis et al. (2012) and Williams (2002) researched translanguaging in primary schools in Wales and concluded that it contributes to the development of language skills and overall achievement. Studying nursery and primary school children's writing processes in New York, Velasco and García (2014) wrote that translanguaging enabled children to self-regulate and to express their 'voice'. Studies carried out with adolescents and adults confirm that translanguaging helps learners to communicate, construct knowledge, raise achievement and mark their identities (Canagarajah, 2011; Creese \& Blackledge, 2010; García \& Li Wei, 2014). It can also contribute to the development of critical thinking skills and deepen sociopolitical engagement (García \& Li Wei, 2014). While translanguaging, the learners may use multimodality, clarify, model, paraphrase and translate (Canagarajah, 2011; Esquinca et al., 2014; Velasco \& García, 2014). Few studies have investigated child-directed translanguaging. The children in the present research project have the opportunity to use their entire repertoire for learning, while producing texts with iTEO outside the classroom.

\section{Fostering collaboration and developing speaking skills through mobile- assisted language learning}

Mobile technologies are now a common feature of language and literacy classes. However, it is still unclear how they contribute to learning (Hutchison \& Beschorner, 2015). Improved learning outcomes are in general related to student engagement, which, in turn, is influenced by the multimedia content, the opportunity to control the language and the interactions, and the playfulness of the activities (Kervin, 2016). For instance, content-free tools can engage users and encourage learning (McEwen \& Dubé, 2015). In order to study the impact of interactions for learning, deHaan and Johnson (2012) asked Japanese students to video-record press conference scenarios and upload them to a wiki. The researchers reported that the interactions between both the university students and between the students and the teacher led the students to reflect about language and enabled them to improve their speaking skills. 
Of particular relevance to the present article are storytelling apps because they can be content-free, encourage talk, and promote collaboration and interaction. Storytelling mobilises linguistic and cultural resources, gives the narrators a 'voice' and contributes to the development of their identity (Cummins, 2006). Digital storytelling may increase opportunities for language learning because it allows learners to weave together pictures, sounds, movies and narration. In addition, it emphasises the learners' roles as author and editor, and enhances their autonomy. It also increases opportunities for collaboration, negotiation and sharing (Sadik, 2008). Finally, storytelling contributes to the development of core social skills and cultural competences needed to become successful members of today's participatory culture (Jenkins, Clinton, Purushotma, Robison, \& Weigel, 2006).

Several researchers found that storytelling apps promoted collaboration and enhanced language learning. Di Blas and Paolini (2013), for example, demonstrated that their largescale storytelling initiative PoliCultura enabled the participating children and adolescents to improve their listening and speaking skills. Similar findings, albeit from smaller studies, come from Kucirkova, Messer, Sheehy, and Panadero (2014) who investigated the use of storytelling apps with 4-5-year-old Spanish children. Moreover, Pellerin (2014) reported language development in her study on the use of the iPod and apps to invent and record stories and puppet shows. The 6-7-year-olds in the Canadian immersion classes were motivated to produce texts, reflected on the language used and made multiple recordings when dissatisfied with the first. In Luxembourg, Gretsch and Kirsch researched the use of iTEO after the completion of the piloting phase of the app in 2012. Kirsch and Bes (2017) found that the 6-7-year-olds collaboratively constructed oral texts on iTEO and provided each other with feedback that led to the learning of new words and sentence structures. While the above-mentioned studies on storytelling apps indicate that children collaborated, they did not shed light on the learners' use of language(s) while producing stories. The present paper will look at the ways in which children deploy their entire language repertoire while working on iTEO.

\section{Researching translanguaging at school in Luxembourg}

Researchers operating within a sociocultural perspective wish to understand complex educational practices within their political and sociocultural context. In order to gain detailed contextualised accounts of practices, they tend to use observation, interviews, documentary evidence and video-recordings. While some focus on recurring patterns, others are more interested in key moments. Li Wei (2011), for example, suggested focusing on innovative moments and analysing spontaneous interactions. This 'moment analysis' investigates possible reasons and consequences of a particular event (Li Wei, p. 1124).

The present paper draws its data from a larger qualitative, longitudinal project (20132017) that studied the use of iTEO in language learning activities in several nursery and primary school classes. The aims of this article are to contextualise and analyse the translanguaging practices of the nursery and primary school children when they work on iTEO and examine the purposes of translanguaging. The research questions read as follows:

- To what extent do language policies and the teachers' language use in the classroom influence the children's translanguaging practices? 
- Why, in what ways and how frequently do children translanguage in interactions with peers when they produce oral texts on iTEO?

The data used for the present paper were collected over two academic years in one of the nursery and one of the primary school classes involved in the project with each teacher responsible for a two-year cycle. Both teachers were experienced. All focus children grew up speaking a language other than Luxembourgish at home. Together with the teachers, we chose children who spoke French, Portuguese, English or other non-national languages at home. Even though French is an official language, the education system focuses at first on Luxembourgish and German. French-speaking children may not be allowed to draw on their knowledge of French until they are in Year 2. Our sample included the focus children as well as the peers they collaborated with when working with iTEO. Table 1 provides details of the two classes, the four focus children and one of the peers named Lina.

This small-scale study cannot be representative of the country as a whole but the sample of the entire project reflects the language diversity typical of Luxembourg. In addition, the longitudinal perspective offers insights into changes in translanguaging practices when children move from nursery to primary school. The changing learning context more languages, a different curriculum - is likely to impact on the children's language use.

The research team used observations, video-recordings and interviews to collect data. A research-assistant spent one day every six weeks in these two classes in order to observe and make detailed field notes of the language use of the teachers and the children. In addition, she video-recorded one teacher-directed activity with ITEO and one involving children working independently. While the nursery children recorded stories in a chosen language at any point during the day, the primary school children recorded texts mainly during the timetabled German or French lessons. The children worked outside the classroom on most occasions. In addition to the video-recordings, the assistant conversed every six weeks with the teachers and the children about their language use and the use of iTEO. Kirsch carried out five semi-structured interviews with each teacher. She asked, for example, what languages teachers and children used and when and why, what activities teachers planned for language learning, how they embedded iTEO in their daily practices and what progress the children made in the target languages. Table 2 provides an overview of the type and quantity of data collected and used in the present article.

The thematic data analysis was assisted by the Nvivo software. The team members began by describing and transcribing the video-recordings. Detailed descriptions are necessary as language use in general, and translanguaging in particular, is multimodal. Young children express themselves holistically through performing actions, using gestures and mimes. While the descriptions enabled the team to identify non-verbal means of

Table 1. Overview of the classes and participants.

\begin{tabular}{llc}
\hline & Nursery school & Year 1/ 2 \\
\hline Number of children & 18 & 18 \\
Children speaking Luxembourgish at home & 9 & 16 \\
Languages spoken at home & $\mathrm{L}, \mathrm{P}, \mathrm{F}, \mathrm{E}, \mathrm{I}, \mathrm{B}, \mathrm{Se}$ & $\mathrm{L}, \mathrm{P}, \mathrm{F}, \mathrm{I}, \mathrm{Sp}$ \\
Focus children and the languages spoken at home & Benjamin (E) & Aaron (F, Ewe) \\
& Diego (F and some I) & Flavio (P, L) \\
Peers & & Lina (Sp, L) \\
\hline
\end{tabular}

Notes: The following abbreviations are used: L, Luxembourgish; P, Portuguese; F, French; E, English; I, Italian; B, Bosnian; Se, Serbian; Sp, Spanish. 
Table 2. Overview of the data collection.

\begin{tabular}{lcccc}
\hline & $\begin{array}{c}\text { Nursery school } \\
\text { Number of } \\
\text { times }\end{array}$ & $\begin{array}{c}\text { Hours } \\
\text { (approx.) }\end{array}$ & $\begin{array}{c}\text { Number of } \\
\text { times }\end{array}$ & $\begin{array}{c}\text { Hours } \\
\text { (approx.) }\end{array}$ \\
\hline $\begin{array}{l}\text { Recordings of the focus children working on iTEO } \\
\text { Recordings of the teachers interacting with the }\end{array}$ & 27 & 10 hours & 27 & 6 hours \\
$\quad$ children & 8 & 2.5 hours & 8 & 2.5 hours \\
$\begin{array}{l}\text { Interviews with the teachers } \\
\text { Conversations with the children }\end{array}$ & 5 & 2.5 hours & 5 & 2.5 hours \\
\hline
\end{tabular}

communication, the transcriptions revealed moments where teachers and children used features of several languages.

In order to examine the language use in the classrooms, the researchers identified all interactions between the focus children and between the teachers and the children, and coded these according to the language, the speaker and the type of activity (i.e. singing, narrating, practising vocabulary). They combined these findings with those from the teachers' interviews, which provided further insights into the reasons for using particular languages. Next, they identified situations where the children translanguaged while working on iTEO and examined these according to the child, frequency, moment (before, during and after recording text) and the text genre produced (e.g. song, story, structured exercise). In order to determine the frequency of translanguaging, the team first determined any 'observations with instances of translanguaging'. These are observations where a pupil translanguaged at least twice. (It would have been impossible to count each instance of translanguaging as the children moved flexibly and quickly between the languages.) The frequency was calculated as a percentage, based on the total number of video-recorded observations and 'the observations with instances of translanguaging'.

Finally, regarding the purposes of translanguaging, the researchers examined the instances of translanguaging according to the children's intention (i.e. communication, knowledge-construction, identity performance).

The project abided by the ethical principles of the University of Luxembourg. The researchers protected the dignity of all participants and asked teachers and parents for informed consent. They have chosen not to remain anonymous and agreed to our posting of videos of iTEO practices on our blog https://teonation.lu in order to disseminate the findings.

\section{Multilingual practices in the classrooms}

This section will begin with a description of the language routines and the use of ITEO in order to situate the translanguaging practices in both classes and examine the ways in which translanguaging is influenced by the classroom practices. The frequency of the children's translanguaging when working with this app will be indicated and the languages used in each setting will be presented. Finally, two excerpts of the nursery and primary school children producing texts are discussed in order to provide additional details of the ways in which they translanguaged.

\section{Language routines in the multilingual classrooms}

The use of multiple languages was the norm in the nursery and the primary school class although there was a clear focus on the target languages German and French in the latter 
(Kirsch, 2014; Kirsch \& Gretsch, 2015). The data analysis revealed that both teachers taught greetings and songs in several languages. Each morning, the primary school children sang a greeting in Portuguese, Italian, Albanian, English, Russian, Vietnamese, Chinese or Kirundi. At times, both teachers addressed native-speakers in their home languages - if known. They explained in the interviews that they wished to connect at a deeper level with these children and aimed at developing positive attitudes towards languages and language learning in all children.

The nursery teacher regularly encouraged the 18 pupils to use their home languages. She explained that 'the children felt much freer when they realised that the use of a language other than Luxembourgish was accepted' (interview, 4.6.15). The children mostly spoke Luxembourgish in class but they used home languages either when they did not know how to express themselves in Luxembourgish or when they felt the need to support another child. The teacher was a good role model in that she tried to learn words in languages unknown to her. For example, when speaking about animals, she asked the children to name them in the home languages and then used these words herself. She also invited family members to school in order to read in a home language. As evident in the video-recordings, she ensured that she, the parents and the nativespeaking children scaffolded the understanding of the other children through pictures, gestures, actions and translations.

While the children in the nursery class had daily opportunities to draw on their entire language repertoire, the field notes and the video-recordings in the primary school class indicated that these children rarely used their home languages. On one occasion, they were asked to produce a text on ITEO at home. For this purpose, Aaron recorded his mother, who originates from Togo, speaking Ewe to his sister. Flavio and Lina produced a text in Portuguese and Spanish, respectively. The purpose of these activities, the multilingual songs and the teacher's translanguaging was the development of language awareness. In his words: 'I use translanguaging deliberately using dialects and my minimal knowledge of Portuguese (...) and Italian, in order for the pupils to hear what it sounds like. (...) I like to draw out their language awareness' (interview, 9.12.14).

\section{The use of ITEO and translanguaging in the nursery class}

Storytelling was a key activity in the nursery class (Kirsch et al., 2014). The teacher explained that she perceived 'the culture of storytelling as an intuitive approach for children' and 'as "the" method to help children learn' because it builds on their resources and promotes language use (interview 30.1.2014). She regularly read stories and took down the children's. The children played, drew, narrated, acted out stories and used iTEO whenever they wished. Taking responsibility over their learning, they selected a partner, a language and a genre, and took account of their peer's needs. The teacher explained:

We have great storytellers and they speak with appropriate rhythm in order to keep the other children focused, concentrated. (...) It is fantastic to see how children think and construct together. Somebody narrates, suddenly looks for a word and another one provides the word. (Interviews, 13.10.14 and 2.3.15) 
The data analysis of the video-recordings indicated that all activities were child-initiated and that the genres of the recorded texts encompassed stories, fairy-tales, retellings of stories, reports of experiences and songs. As for translanguaging, the focus children were found to draw on their entire repertoire on most occasions, using Luxembourgish, a home language, and features of other languages picked up from peers. For example, Diego was observed recording texts in French on nine occasions, once singing in Arabic and twice in English. When interacting with Benjamin, he translanguaged using features of English in one observation. Benjamin recorded some French texts with Diego's help on three occasions. He also used German in one video-recording and some formulaic Portuguese in another. Table 3 indicates the frequency of translanguaging and Table S1, the languages used.

The teacher encouraged the children to listen to iTEO stories in languages other than Luxembourgish. The authors learned to provide contextual clues, paraphrase and translate. The listeners learned to pay attention to cognates and oral clues (e.g. intonation) and ask for clarification. These skills enabled children to convey and make meaning while translanguaging.

\section{The use of ITEO and translanguaging in the primary school class}

In Year 1 and Year 2, iTEO was used both for unstructured and structured language learning activities (Kirsch \& Gretsch, 2015). For example, the teacher allowed the children to use the app to sing and record stories in any language. He also designed more structured activities to teach German and French, particularly so from the end of Year 1. Examples include exercises to develop narrative skills and vocabulary practice. He regularly involved the French native-speakers in the French lessons in Year 2. He asked Aaron, for example, to practise vocabulary and sentence structures with his peers. On these occasions, Aaron moved flexibly between French and Luxembourgish. The teacher maintained:

I am lucky to have French-speaking children in my class. This is a valuable resource when we work with iTEO. (...) Aaron is eager to teach his peers. (Interviews on 9.12.14 and 8.3.15)

Of the 27 video-recordings of the children using iTEO, 19 represented child-initiated activities. The children once recorded a song and a further eight times stories and reports of experiences. On 10 occasions, they designed exercises to practise French. In 24 of the 27 video-recordings, they dynamically switched between Luxembourgish and either German or French. Table 3 documents this high frequency of translanguaging for each focus child. Table S1 indicates that Aaron and Flavio used the target

Table 3. Frequency of translanguaging of the nursery children while working on iTEO.

\begin{tabular}{clccc}
\hline & $\begin{array}{c}\text { Number of } \\
\text { observations }\end{array}$ & $\begin{array}{c}\text { Number of observations with instances of } \\
\text { translanguaging }\end{array}$ & $\begin{array}{c}\text { Frequency of } \\
\text { translanguaging (\%) }\end{array}$ \\
\hline $\begin{array}{c}\text { Nursery } \\
\text { school }\end{array}$ & Benjamin & 24 & 12 & 50 \\
\multirow{2}{*}{$\begin{array}{c}\text { Primary } \\
\text { school }\end{array}$} & Aiego & 16 & 10 & 63 \\
& Faron & 17 & 16 & 94 \\
\hline
\end{tabular}


languages German and French most, in addition to Luxembourgish. Aaron used French during six recordings, of which four happened in Year 2. By contrast, Flavio used Portuguese only once. The children once recorded a song in Korean.

So far, the findings have shown that the teachers' language use, the multilingual routines, the curriculum and the variety of activities on iTEO familiarised children with a range of language practices and influenced the ways in which they translanguaged. The nursery children came to understand that it was acceptable and desirable to use all features of their language repertoire and they translanguaged regularly. The primary school children learned to value a range of language practices although they realised that the aim was to learn to communicate accurately in the target languages. They moved flexibly between Luxembourgish and the target languages and seldom used home languages except for French and only in Year 2. The following two sections will detail the processes and purposes of translanguaging.

\section{Translanguaging during a digital storytelling activity in the nursery class: Benjamin and Diego}

The excerpt below focuses on Benjamin and Diego who began to learn Luxembourgish aged 3 in the précoce. At home, Diego spoke French with his mother and French and some Italian with his father. Benjamin spoke English at home. He understood some French because his parents had enrolled him as an infant in a crèche with French-speaking staff. The excerpt shows how Diego (D) and Benjamin (B), both aged 5, moved between Luxembourgish and French while recording a story and two songs. In the English translation, Luxembourgish is presented in normal script and French in italics. The automatic replay of iTEO is in bold and overlapping text in brackets. The original text can be found in Table S2.

\begin{tabular}{|c|c|c|}
\hline & & Translation of Expert 1 \\
\hline 1 & B & I start. \\
\hline 2 & $\mathrm{D}$ & And I ... \\
\hline 3 & $\mathrm{~B}$ & I can go twice and you go twice. \\
\hline 4 & D & Once upon a time \\
\hline 5 & B & A villain ... But look. No, in French. \\
\hline 6 & D & $\begin{array}{l}\text { OK. } \\
\text { (using a story-telling voice) } \\
\text { Once upon a time there was a very } \\
\text { [bad boy]. }\end{array}$ \\
\hline 7 & B & {$[($ looks up $)]$} \\
\hline 8 & D & $\begin{array}{l}\text { He was in a cavern as dark as black. He was bad. He was invisible. And he took all the } \\
\text { odours that smelt nice and then everything smelt like cow poop. }\end{array}$ \\
\hline 9 & iTEO & Once upon a time there was a very bad boy. \\
\hline 10 & [iTEO] & [He was in a cavern as dark as black.] \\
\hline 11 & 1. $[\mathrm{B}]$ & [Do it again. ] \\
\hline 12 & [iTEO] & {$[\ldots$ invisible ... $]$} \\
\hline 13 & 1. $[\mathrm{B}]$ & [OK, do it again with the garçon. From the beginning, from the beginning.] \\
\hline 14 & iTEO & ... cow poop. \\
\hline 15 & B & What should I? \\
\hline 16 & $\mathrm{D}$ & $\begin{array}{l}\text { (singing) } \\
\quad \text { There was a boy, he was so strong that he }\end{array}$ \\
\hline 17 & B & $\begin{array}{l}\text { OK. (interrupting) } \\
\text { (singing) } \\
\text { It is the boy. It is stone. The boys. You can do the guitars. The guitars are the boys, } \\
\text { the guitars are the boys.\$(smiling) }\end{array}$ \\
\hline
\end{tabular}


This 1.5-minute-long sequence begins with the boys discussing turn taking (lines 1-3). Diego initiates a story but Benjamin interrupts him suggesting input. He then stops and asks Diego to continue in French (line 4). Diego takes up the offer (line 5). He repeats the formulaic beginning in Luxembourgish and then narrates a story in French about a bad boy who catches pleasant odours (lines 6, 8). When he emphasises the word garçon, Benjamin looks up and smiles (line 7). During the automatic replay of the story (lines 9, 10, 12, 14), Benjamin asks Diego three times to play back the word garçon (lines 11, 13). Diego declines and the boys listen to the end of the story. When it is Benjamin's turn to record a text, he asks Diego for a suggestion (line 15). Diego responds by inventing a French song featuring the word garçon (line 16). Imitating his friend, Benjamin creates a song in French (line 17).

In this safe and meaningful learning environment, translanguaging happened both by invitation (e.g. from Benjamin) and by choice (e.g. Diego singing). Benjamin invited his friend to speak French although he knew that he would not understand everything. Diego was aware of his friend's competences and provided comprehension clues through his multimodal performance. He adopted a storytelling voice, gestured and mimed. In this way, Benjamin was able to notice key words such as garçon. He repeated this word and asked for replays. Diego drew on his friend's interest in French. He used garçon in the context of a song, which prompted Benjamin to create a song where he mobilised all the French phrases he knew. He was now able to perform in French thanks to Diego's input and feedback, and owing to his repeating, memorising and using phrases in new ways.

When conversing about storytelling with the research-assistant, the boys indicated a preference for Luxembourgish. They also explained that they used a home language because, in Diego's words, 'I feel both French and Luxembourgish'. Benjamin and Diego, like their peers, used their entire repertoire to develop multilingualism and mark a multilingual identity. For example, Diego referred to Blanche-Neige rather than Snow-white and his Portuguese-speaking peer Mariana closed her stories with amigos para sempre. Children who shared a home language, for example, Diego and another French-speaking child, tended to translanguage for ease of communication as well. They would, for example, record a text in Luxembourgish and discuss turn-taking rules or negotiate the genre or content of a text in their home language.

\section{Translanguaging during digital storytelling in the primary school class: Aaron and Lina}

The following excerpt from May 2015 shows how 7-year-old Aaron and Lina tell a story in French. Lina, then in Year 2, had been formally learning French for 3 months. French-native speaker Aaron (A) came to Luxembourg aged 4 and learned Luxembourgish in the nursery school. Lina (L) was born in Luxembourg to Spanish-speaking parents and communicates in Luxembourgish and Spanish at home. The transcript follows the same conventions as the previous one. The original text is displayed in Table S3. 


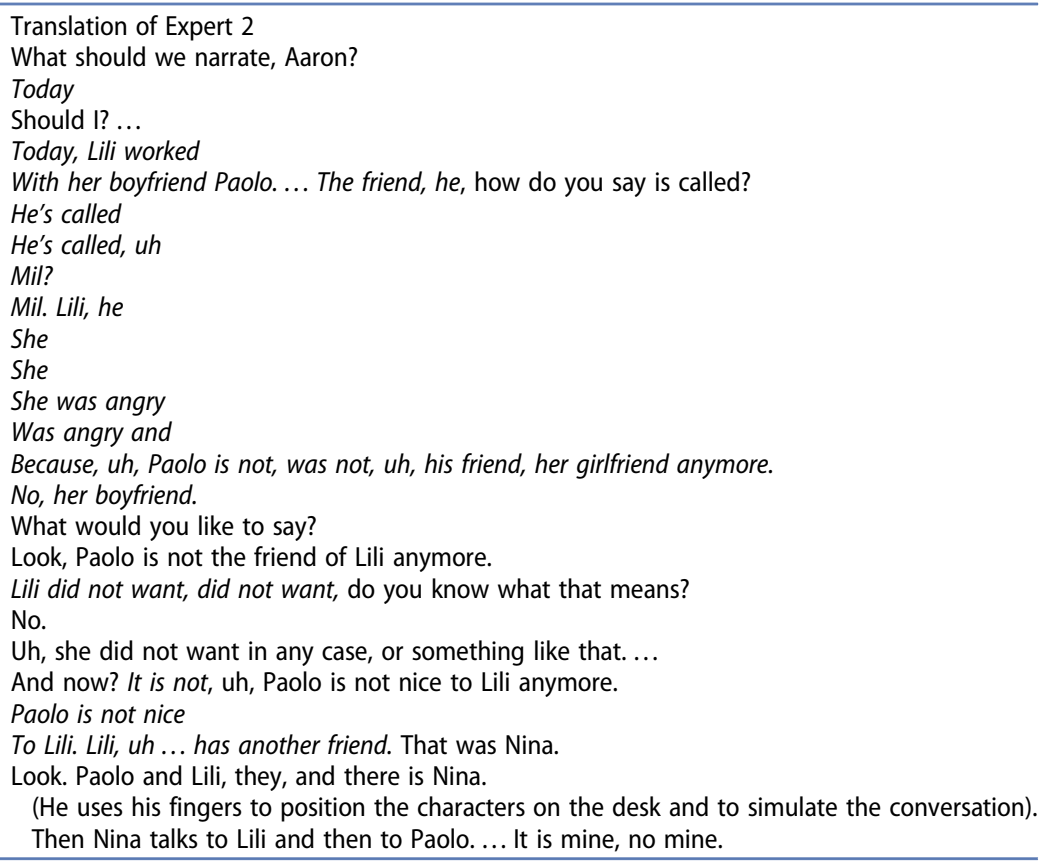

This story is about Lili and Paolo who fall out, possibly because of Lili's friend Nina. Lili and Nina both state that Paolo is 'hers'. While the story is in French, the process of co-constructing is bilingual. In lines 1 and 3, Lina asks Aaron in Luxembourgish what they should narrate and whether she can take a turn. In line 5, she switches to French and completes the French sentence Aaron began. However, she reverts to Luxembourgish to ask Aaron for a translation. She continues in French thanks to Aaron who makes suggestions, offers lexical input (lines 6, 12, 14) and rephrases an inaccurate part (line 10). Lina accepts the feedback and transforms her text thereby showing evidence of uptake (lines 7, 9, 11, 13). Next, she carefully listens to Aaron, notices his lexical error (line 14) and rephrases his French sentence. In Luxembourgish, Aaron asks her to explain what she means (line 16) possibly because the switch of roles confused him. The 'novice' has corrected the 'expert'. Lina accepts the request and gives an explanation, thereby demonstrating her understanding of when to use copain/copine (line 17). Aaron initiates the next sentence in French but interrupts himself and asks Lina in Luxembourgish if she has understood. He then translates (line 20). In lines 21 and 23, Lina moves back and forth between the home and the target languages. She asks for a suggestion of how to continue, begins a sentence in French, stops and volunteers an idea in Luxembourgish. She thereby hints at her inability to phrase it in French. Aaron translates (line 22) and draws on her idea to develop the plot (line 24). As this is complex, he reverts to Luxembourgish and uses his fingers to illustrate the story. The thumb and second fingers of his right hand represent Lili and Paolo, and the second finger of his left hand Nina. 'Nina' moves towards 'Lili' and 'Paolo' and then between them.

In this excerpt, translanguaging enabled the children to co-construct a story in French. Although the language use was dynamic, the languages fulfil particular roles. The children used French to narrate and provide input by translating and rephrasing, and 
Luxembourgish to communicate about turn-taking and the content of the story, clarify a meaning and demonstrate understanding. Aaron, who had been learning Luxembourgish for 4 years, also acted in order to express complex ideas.

The video-recordings of this and other language learning activities reveal that the primary school children translanguaged for three purposes: communication, knowledge construction and identity performance. First, they used their entire repertoire to negotiate content, assess a performance, praise and discuss turn-taking. Second, they made meaning and constructed knowledge through asking for translations, providing lexical input, explaining, clarifying, rephrasing, demonstrating, understanding and discussing about a language issues. Finally, translanguaging enabled them to position themselves as multilinguals. They developed competence in the target languages and, on a few occasions, recorded texts in Spanish, Portuguese or Korean.

\section{Discussion}

This article contextualised translanguaging practices of 4-7-year-olds and explored the purposes thereof. The findings show that translanguaging was valid, frequent and legitimate in the nursery and primary school class. This particular outcome contrasts with studies by Creese and Blackledge (2010) and Jonsson (2013) who found that translanguaging was uncommon in mainstream and community schools. The findings also indicate, in line with García and Li Wei (2014) and Velasco and García (2014), that young bilinguals, in this case emergent multilinguals, are able to translanguage strategically. They drew on features of four and more languages rather than two, unlike the children in the above-mentioned studies.

As for the purposes of translanguaging, it was shown to first facilitate communication and contribute to language learning. In line with García and Sylvan (2011) and Wiley and García (2016), translanguaging will help these young learners develop their multilingual repertoire. On the one hand, they develop competences in a range of named languages. For instance, both excerpts presented in this article illustrated how the children used and learned new words. They analysed languages, suggested corrections and assessed a performance. Such performances will lead to competence (Cazden, 1997). On the other hand, translanguaging promotes the development of a multilingual competence. Children learn when and where to select, but also to suppress, particular features of their repertoire, and how to use languages appropriately in order to meet the demands at hand. For instance, the children in the primary school class began to understand that using French was valued and legitimate in Year 2 when French was a curricular language. A final purpose of translanguaging identified in the present study, as well as those by, for example, García and Li Wei (2014) and Creese and Blackledge (2010), is the enactment of the learners' multilingual identities. The children displayed their awareness that it was acceptable for multilinguals to move between languages and did so. In sum, the purposes of translanguaging of these emergent 4-7-year-old multilinguals were similar to those of older pupils, adolescents and adults investigated in the above-mentioned studies. This raises questions of the relevance of age and experience of using multiple languages in relation to the strategic use of translanguaging.

As shown in the present paper, the children' ability to move flexibly between languages has also to be seen in relation to a particular context, in this case, the everyday practices of 
a multilingual country, the routine language practices at school and the language activities performed on the app iTEO. In Luxembourg, children have the opportunity to experience the dynamic use of multiple languages through face-to-face interactions and the media. By contrast, language teaching at primary school is often formal and compartmentalised (De Korne, 2012). The curriculum with its focus on three languages impacts on the 'macro framework for translanguaging' (García \& Hesson, 2015, p. 227). The primary school children investigated were not given many opportunities to draw on home languages other than Luxembourgish and, in Year 2, French. Looking at the 'micro framework for translanguaging', the findings indicate that both teachers acted as models in that they used a range of languages in a range of situations with the aim of fostering language awareness and promoting multilingualism. They offered translanguaging spaces similarly to the teachers investigated elsewhere (Canagarajah, 2011; Creese \& Blackledge, 2010; García \& Hesson, 2015). They also designed language-learning activities that allowed for peer-grouping and the use of digital technologies.

Storytelling tasks in combination with the benefits of the app iTEO offer spaces where children can mobilise their entire language repertoire, collaboratively construct texts and support each other's language learning. The children described in this article took responsibility: they decided on the languages, the genre, the content and the partner, and created meaningful texts that expressed their 'voice' (Cummins, 2006). They were engaged and motivated similarly to the children in the studies of Di Blas and Paolini (2013), Kucirkova et al. (2014) and Pellerin (2014). They listened carefully, asked for help and assisted each other. They had opportunities to dialogue, repeat, imitate, analyse, transform and speak about language use. These actions and strategies scaffold learning as demonstrated in the studies of, for example, Velasco and García (2014) and Angelova, Gunawardena, and Volk (2006). Both teachers gave collaborative digital storytelling a place in their classroom, although in different ways and for different reasons. The nursery class teacher described storytelling as an intuitive way to learning that capitalises on the children's resources. She gave the class daily opportunities to invent, tell, draw and play stories. The primary teacher valued the development of language awareness and conscious reflection on language that came from the children giving each other feedback on their oral productions. He viewed iTEO as a flexible 'language learning tool' (Kirsch \& Bes, 2017; Kirsch \& Gretsch, 2015, p. 45).

\section{Concluding remarks}

The findings have shown that the emergent multilingual children investigated of this study translanguaged frequently and that this legitimate practice allowed them to communicate, construct knowledge and enact a multilingual identity. The social, linguistic and identity functions of translanguaging discussed above reinforce the need to develop translanguaging practices in classrooms elsewhere. As shown in this article, digital language learning tasks such as those performed on iTEO can offer learners valuable opportunities to develop their multilingual repertoire.

One contribution of this article comes from the analysis of translanguaging practices within its particular context. It highlights the language ideologies and hegemonic forces in the educational system that prompt professionals, here mainly primary school teachers, to value particular languages and language practices over others. For example, the 
children's knowledge of French was legitimised and capitalised on in Year 2 once this language became a curricular language. Although the multilingual children investigated translanguaged frequently in primary school, it is noteworthy that they only drew on some parts of their language repertoire and never produced a translingual text. They moved strategically between the official languages in order to develop competences in the target languages. While mastery of languages is certainly an important educational objective, schools, particularly those in multilingual settings, should also ensure that learners develop a multilingual competence, thus their ability to use languages appropriately and effectively according to the demands at hand.

In order to ensure that researchers and teachers develop a fuller understanding of translanguaging as a leverage for language learning and learning in general, we need both more research and more outreach work to professionals. Further research could examine the teachers' perspectives on translanguaging as these are likely to impact on their practices. While the nursery teacher in the present study seemed to perceive the identity function of translanguaging as particularly relevant, the primary teacher valued its affordance for raising language awareness and constructing linguistic knowledge. Further studies could examine, first, in what ways new technologies can foster translanguaging practices, and, second, the extent to which translanguaging contributes to language development. Although the present study did not measure language competences, the researchers noticed development over two years. The focal children in the nursery and the primary school had little knowledge of the target languages at the beginning of the project and the continuous input contributed to their developing competences. Translanguaging offered the children the necessary space and time to learn new languages confidently while drawing on all available resources. Studies with a pre/ post design may help us improve our understanding between translanguaging and raising achievement.

\section{Acknowledgements}

First, I would like to thank the teachers and pupils as well as the research-assistant Ms Di Letitia for their participation in this research project. I am also grateful to my colleagues Gérard Gretsch and Asunción Bes for their insightful comments. My specials thanks go to Ofelia García and Jean Conteh and the anonymous reviewers and Durk Gorter for commenting on the various drafts.

\section{Disclosure statement}

No potential conflict of interest was reported by the authors.

\section{Funding}

This work was supported by the Université du Luxembourg under Grant PUL R-AGR-0222 and the Ministère de l'Education nationale, de l'Enfance et de la Jeunesse (http://www.men.public.lu/ home/index.html).

\section{References}

Angelova, M., Gunawardena, D., \& Volk, D. (2006). Peer teaching and learning: Co-constructing language in a dual language first grade. Language and Education, 20(3), 173-190. 
Canagarajah, S. (2011). Codemeshing in academic writing: Identifying teachable strategies of translanguaging. Modern Language Journal, 95(3), 401-417.

Cazden, C. B. (1997). Performance before competence: Assistance to child discourse in the zone of proximal development. In M. Cole, Y. Engeström, \& O. Vasquez (Eds.), Mind, culture, and activity: Seminal papers from the laboratory of comparative human cognition (pp. 303-310). Cambridge: Cambridge University Press.

Creese, A., \& Blackledge, A. (2010). Translanguaging in the bilingual classroom: A pedagogy for learning and teaching? The Modern Language Journal, 94(1), 103-115.

Cummins, J. (2006). Identity texts: The imaginative construction of self through multiliteracies pedagogy. In O. García, T. Skutnabb-Kangas, \& M. E. Torres-Guzmán (Eds.), Imagining multilingual schools. Language in education and globalization (pp. 51-68). Clevedon: Multilingual Matters.

De Korne, H. (2012). Towards new ideologies and pedagogies of multilingualism: Innovations in interdisciplinary language education in Luxembourg. Language and Education, 26(6), 479-500.

deHaan, J., \& Johnson, N. H. (2012). Enhancing the scenario: Emerging technologies and experiential learning in second language instructional design. The International Journal of Learning, 18(4), 322333.

Di Blas, N., \& Paolini, P. (2013). Beyond the school's boundaries: PoliCultura, a large-scale digital storytelling initiative. Journal of Educational Technology \& Society, 16(1), 15-27.

Esquinca, A., Araujo, B., \& de la Piedra, M. T. (2014). Meaning making and translanguaging in a twoway dual-language program on the U.S.-Mexico border. Bilingual Research Journal, 37(2), 164-181.

Fehlen, F., \& Heinz, A. (2016). Die Luxemburger Mehrsprachigkeit. Ergebnisse einer Volkszählung. Luxemburg: Transcript-Verlag.

García, O. (2011). Translanguaging of Latino kindergardeners. In K. Potowski, \& J. Rothman (Eds.), Bilingual youth: Spanish in English speaking societies (pp. 33-55). Amsterdam: John Benjamins.

García, O., \& Flores, N. (2011). Multilingual pedagogies. In M. Martin-Jones, A. Blackledge, \& A. Creese (Eds.), The Routledge handbook on multilingualism (pp. 232-242). London: Routledge.

García, O., \& Hesson, S. (2015). Translanguaging frameworks for teachers: Macro and micro perspectives. In A. Yiacoumetti (Ed.), Multilingualism and language in education: Current sociolinguistic and pedagogical perspectives from commonwealth countries (pp. 221-242). Cambridge: Cambridge University Press.

García, O., \& Li, W. (2014). Translanguaging: Language, bilingualism and education. New York: Basingstoke: Palgrave.

García, O., \& Sylvan, C. (2011). Pedagogies and practices in multilingual classrooms: Singularities in pluralities. The Modern Language Journal, 95(3), 385-400.

Haukas, Å. (2016). Teachers' beliefs about multilingualism and a multilingual pedagogical approach. International Journal of Multilingualism, 13(1), 1-18.

Hornberger, N. H., \& Link, H. (2012). Translanguaging and transnational literacies in multilingual classrooms: A biliteracy lens. International Journal of Bilingual Education and Bilingualism, 15(3), 261278. Retrieved from http://www.statistiques.public.lu/stat/TableViewer/tableView.aspx?Reportld= 12853\&IF_Language $=$ eng\&MainTheme $=2 \& F I d r$ Name $=1 \&$ RFPath $=69$

Hutchison, A., \& Beschorner, B. (2015). Using the iPad as a tool to support literacy instruction. Technology, Pedagogy and Education, 24(4), 407-422.

Jacobson, R., \& Faltis, C. (1990). Language distribution issues in bilingual schooling. Clevedon: Multilingual Matters.

Jenkins, H., Clinton, K., Purushotma, R., Robison, A. J., \& Weigel, M. (2006). Confronting the challenges of participatory culture: Media education of the 21st century. Chicago, IL: MacArthur Foundation.

Jonsson, C. (2013). Translanguaging and multilingual literacies: Diary-based case studies of adolescents in an international school. International Journal of the Sociology of Language, 224, 85-117.

Kervin, L. (2016). Powerful and playful literacy learning with digital technologies. Australian Journal of Language and Literacy, 39(1), 64-73.

Kirsch, C. (2014). Storytelling at home and at the nursery school: A study of bilingual children's literacy practice. In N. Morys, C. Kirsch, I. de Saint Georges, \& G. Gretsch (Eds.), Lernen und Lehren in multilingualen Kontexten: Zum Umgang mit sprachlich-kultureller Vielfalt im Klassenraum (pp. 219-246). Frankfurt: Peter Lang. 
Kirsch, C, \& Bes, A. (2017). Emergent multilinguals learning languages with the iPad app iTEO: A study in primary schools in Luxembourg. Language Learning Journal. doi:10.1080/09571736.2016. 1258721.

Kirsch, C., \& Gretsch, G. (2015). L'apprentissage langagier avec l'App iTEO.-Multilinguisme: enseignement, littératures et cultures au Luxembourg. Synergies Pays Germanophones, 8, 37-48.

Kucirkova, N., Messer, D., Sheehy, K., \& Panadero, C. F. (2014). Children's engagement with educational iPad apps: Insights from a Spanish classroom. Computers \& Education, 71, 175-184.

Lewis, G., Jones, B., \& Baker, C. (2012). Translanguaging: Developing its conceptualisation and contextualization. Educational Research and Evaluation: An International Journal on Theory and Practice, 18(7),655-670.

Li Wei. (2011). Moment analysis and translanguaging space: Discursive construction of identities by multilingual Chinese youth in Britain. Journal of Pragmatics, 43, 1222-1235.

Martin, R., Ugen, S., \& Fischbach, A. (2015). Épreuves Standardisées: Bildungsmonitoring für Luxemburg. Nationaler Bericht 2011 bis 2013. LUCET, University of Luxembourg.

McEwen, R., \& Dubé, K. (2015). Engaging or distracting: Children's tablet computer use in education. Educational Technology \& Society, 18(4), 9-2.

Ministry of Education and Professional Development. (2011). Plan d'études. Ecole fondamentale. Luxembourg: Ministère de l'Education Nationale et de la Formation Professionnelle.

Ministry of National Education, Childhood and Youth. (2016). Les chiffres clés de l'Éducation nationale: statistiques et indicateurs - Année scolaire 2014-2015. (Août 2016). Retrieved from http://www.men. public.lu/catalogue-publications/themes-transversaux/statistiques-analyses/chiffres-cles/20142015/CC_201415.pdf

Otheguy, R., García, O., \& Reid, W. (2015). Clarifying translanguaging and deconstructing named languages: A perspective from linguistics. Applied Linguistics Review, 6(3), 281-307.

Pellerin, M. (2014). Language tasks using touch screen and mobile technologies: Reconceptualizing task-based CALL for young language learners. Canadian Journal for Learning and Technology, 40(1), Retrieved from http://www.cjlt.ca/index.php/cjlt/article/view/26295

Pennycook, A. (2010). Language as a local practice. London: Routledge.

Sadik, A. (2008). Digital storytelling: A meaningful technology-integrated approach for engaged student learning. Educational Technology Research and Development, 56(4), 487-506.

Velasco, P., \& García, O. (2014). Translanguaging and the writing of bilingual learners. Bilingual Research Journal, 37(1), 6-23.

Wiley, T. E., \& García, O. (2016). Language policy and planning in language education: Legacies, consequences, and possibilities. The Modern Language Journal, 100(S1), 48-63.

Williams, C. (2002). Extending bilingualism in the education system (Education and Lifelong Learning Committee Report ELL-06-2, p. 4). Retrieved from http://www.assemblywales.org/ 3c91c7af00023d820000595000000000.pdf 